Brazilian Journal

of Chemical

ISSN 0104-6632

Printed in Brazil

Engineering

www.scielo.br/bjce

Vol. 35, No. 02, pp. 623 - 630, April - June, 2018

dx.doi.org/10.1590/0104-6632.20180352s20160395

(cc) BY

\title{
SYNTHESIS OF ZEOLITE 4A FOR OBTAINING ZEOLITE 5A BY IONIC EXCHANGE FOR FULL UTILIZATION OF WASTE FROM PAPER INDUSTRY
}

\author{
Jarina Costa Moreira ${ }^{1 *}$, Rozineide Aparecida Antunes Boca Santa ${ }^{1}$, \\ Janaína Nones ${ }^{1}$ and Humberto Gracher Riella ${ }^{1}$ \\ ${ }^{1}$ Departmentof Chemical Engineering, Federal University of Santa Catarina, P. O. \\ Box 476, Trindade, Florianópolis, SC, 88.040-900, Brazil
}

(Submitted: March 22, 2016; Revised: December 16, 2016; Accepted: December 25, 2016)

\begin{abstract}
In order to minimize environmental impact zeolite A was synthesized using waste from the paper industry. This waste is composed of cellulose, kaolin and calcium carbonate. Waste purification was carried through thermal and chemical treatment, which consisted of initial calcination, acid washing with $\mathrm{HCl}$, then calcination of the solid fraction to obtain metakaolin and evaporation of the liquid fraction to obtain $\mathrm{CaCl}$. Zeolite $4 \mathrm{~A}$ was produced by static autoclaving under hydrothermal synthesis at different temperatures, crystallization times and $\mathrm{NaOH}$ concentrations. As a source of aluminum and silicon metakaolin was used. The synthesis of zeolite $5 \mathrm{~A}$ was performed by ion exchange with $\mathrm{CaCl} 2$. After that, the waste paper (in natura and $\mathrm{HCl}$ treatment) and the zeolites 4A and 5A were characterized by XDR, SEM, FTIR, AAS and thermal analysis. The temperature is a key factor in zeolite synthesis at lower concentrations allowing one to obtain zeolite $5 \mathrm{~A}$ by ion exchange with zeolite $4 \mathrm{~A}$.
\end{abstract}

Keywords: Metakaolin, waste industry, zeolite.

\section{INTRODUCTION}

Highly advanced technology in recent years has been offering many benefits to the growing population, while covering several sectors, in both rural and urban areas. This has led to increased production and improvement in the food industry, the clothing industry, means of transportation, education, information, the construction industry, among others. Thus, faced with great demand for different products, constant needs of consumers, high competition and economic growth, technology and investment must be coordinated and programmed to avoid depletion of natural resources, enhance people's quality of life on the planet and care for the global environmental perspective, aiming at sustainability of present and future generations. One

*Corresponding author: Phone/fax +55 48 37219931; e-mail: jarina_moreira@hotmail.com important aspect that should be considered before, during and after the manufacturing process, as well as at post-consumption, is the growing accumulation of waste. Waste management is an issue that affects the entire world, in view of the high cost of handling, treatment and disposal of waste. Some government agencies are seeking to implement preventive policies in an attempt to reduce the generation of waste while encouraging recycling and reuse (Campos, 2014; Triguero et al., 2016). This will result in less waste and consequently in cost savings by managing and reducing the number of landfills, since this is the cheapest and most common means of waste disposal (Lorenzett et al., 2012). Thus, a survey was conducted to support the economic viability of waste paper pulp treatment from a papel mill within the region under study. The production in the region can reach up to 3000 ton/month of treated waste. The maintenance 
cost of a landfill is, approximately, 6 dollars per ton; however, the treated material can be traded for 50 dollars per ton. Considering the treatment cost, the profit could reach over 17 dollars per ton. The decrease in natural resources extraction has an incalculable value. Paper is a consumer good that covers virtually every sector of the economy because it is incorporated into many uses. For that reason, it is considered as one of the indices for evaluating the standard of living in a given region. Paper consumption has had high growth rates worldwide, which led to an increase in the demand for pulp, the main raw material for paper (Carvalho et al., 2005). Brazil is a major producer of paper because it has advantageous conditions for wood production, e.g., favorable weather for crops such as eucalyptus. According to the Brazilian Pulp and Paper Association, the Brazilian pulp and paper industry consists of 220 companies located in 540 municipalities in 18 states, and 35 companies export their product on a regular basis. The Brazilian pulp production in 2013 totaled 15.1 million tonnes, while paper production totaled 10.4 million tons (BRACELPA, 2015). The figures on the current environmental scenario have led to an increase in the research on renewable materials for environment-focused applications. Waste volume is growing constantly, and alternative use of this waste is needed, primarily as raw materials in other types of industry (Pinheiro et al., 2008). Thus, using waste materials from different industries is important. Such waste is inherent in the production process, and generated on a large scale; if handled properly, it can become by-products for new materials. Solid waste generated in the paper industry is basically composed of kaolin, calcium carbonate and cellulose. Kaolin is one of the materials of greatest interest for zeolite synthesis. In synthesis processes, the demand for more economical raw materials resulted in processes that arise from the use of clay minerals, with kaolin being the most widely used, because these minerals are a natural source of $\mathrm{Al}_{2} \mathrm{O}_{3}$ and $\mathrm{SiO}_{2}$, which are used to replace chemical reagents such as sodium aluminate and silica (Breck,1984). Zeolite synthesis is a multiphase reaction-crystallization process, usually involving at least one liquid phase and solid phases, both crystalline and amorphous phases, stemming from hydrogels such as aluminates and silicates and minerals, such as ash and calcined kaolin. Synthetic zeolites are formed at a temperature ranging from $80{ }^{\circ} \mathrm{C}$ to $200{ }^{\circ} \mathrm{C}$ (Cundy and Cox 2003; Viera et al., 2014). Due to their structural characteristics, zeolites have some unique properties that make them useful in many industrial applications, such as high specific surface area; pores, channels and cavities of molecular dimensions that impart different types of selectivity; high adsorption capacity, ease of separation of reactants and products; high thermal stability associated with higher $\mathrm{Si} / \mathrm{Al}$ ratio and internal acidity, responsible for zeolite action as catalysts (Corma, 2003; Grecco and Rangel, 2013). A wide variety of applications for zeolites includes: agriculture, processing of radioactive materials and contaminated soils, removal of toxic metals, softener of industrial and domestic water, purification and separation of industrial gases, animal nutrition, catalysis and oil refining, as well as other applications (Luna and Schuchardt, 2001; Silaghi et al., 2014; Jamieson et al., 2015). Zeolite A are usually synthesized in the $4 \mathrm{~A}$ sodium structure. When sodium is replaced with calcium, zeolite changes from the $4 \mathrm{~A}$ to the $5 \mathrm{~A}$ structure, and sodium replaced with potassium results in the 3A structure (Loiola et al., 2012; Zhang et al., 2013). In this context, the objective of this research was to produce zeolite $5 \mathrm{~A}$ by ion exchange from the zeolite 4A synthesized from the waste from the paper industry.

\section{MATERIALS AND METHODS}

The sources of silicon and aluminum used in zeolite synthesis were obtained from kaolin and the source of $\mathrm{Ca}^{+2}$ ions used in cation exchange was calcium chloride, both from the waste from paper industries in the state of Santa Catarina, Brazil. At the steps of washing and synthesis, reagents with a high degree of analytical purity were used, e.g., $\mathrm{HCl}$ (Vetec, 37\%) and $\mathrm{NaOH}$ (Vetec, 98\%), respectively. The waste purification process was performed in three steps: the first step consisted of waste calcination at $600^{\circ} \mathrm{C}$ for 2 hours to eliminate organic matter (pulp). In the second step, acid washing of the waste was carried out in $\mathrm{HCl}$ solution at concentrations of 1.5 and $1.8 \mathrm{~mol} . \mathrm{L}^{-1}$, which provided filtered kaolin and calcium chloride (dissolved in the solution) by evaporation of washing water, resulting from the reaction between $\mathrm{HCl}$ and $\mathrm{CaCO}_{3}$ present in the waste. For $150 \mathrm{~g}$ of calcined residue, $1 \mathrm{~L}$ of 1.5 and 1.8 mol. $\mathrm{L}^{-1}$ of $\mathrm{HCl}$ solution was used. After adding the solution, the residue was filtered and the liquid was evaporated on a heating plate at 100 ${ }^{\circ} \mathrm{C}$, obtaining $50 \mathrm{~g}$ of $\mathrm{CaCl}_{2}$ for each liter of solution. The calcium chloride resulting from evaporation was used to obtain zeolite $5 \mathrm{~A}$ by ion exchange. In the last step, kaolin was calcined in a muffle furnace at $850{ }^{\circ} \mathrm{C}$ for 2 hours for conversion into metakaolin. According the geological formation, kaolin has a different mineralogical composition, which influences the 
transformation temperature of kaolin into metakaolin. Studies indicate that the optimal temperature to convert the kaolin from the paper industry waste processing is $850{ }^{\circ} \mathrm{C}$ (Boca Santa et al., 2013). The synthesization process of zeolite 4A was performed using the method proposed by Rigo et al. (2009) and Filho Silva et al. (2015); therefore, the synthesis of zeolite 4A was performed under static autoclaving, based on the hydrothermal reaction of $3 \mathrm{~g}$ metakaolin dissolved in $30 \mathrm{~mL} \mathrm{NaOH}$ solution at concentrations of 1.25 and 4.25 mol. $\mathrm{L}^{-1}$ in a Teflon/aluminum container. The addition of reagents was performed under stirring and, after this procedure, they were oven-dried for 4 to 6 hours at $80^{\circ} \mathrm{C}$ and $150{ }^{\circ} \mathrm{C}$ under autogenous pressure. Aging time was approximately 4 hours. The resulting materials were washed and centrifuged successive times until $\mathrm{pH}$ of about 9 , then the samples were dried at $100{ }^{\circ} \mathrm{C}$ overnight. Zeolite $5 \mathrm{~A}(\mathrm{CaA})$ preparation was carried out by ion exchange with zeolite $4 \mathrm{~A}(\mathrm{NaA})$. The exchangeable cation of the zeolite $4 \mathrm{~A}$ is sodium and, in this case, calcium chloride from the waste was used in the ion exchange as a source of calcium ions $\left(\mathrm{Ca}^{+2}\right)$ in the solution. The ion exchange process was carried out in a batch reactor with water, based on the reaction of $6 \mathrm{~g}$ zeolite $4 \mathrm{~A}$ dissolved in $40 \mathrm{~mL}$ of $\mathrm{CaCl}_{2}$ solution at the concentration of $0.18 \mathrm{~mol}^{-\mathrm{L}^{-1}}$ (Melo et al., 2012). The zeolite $4 \mathrm{~A}$ and the $\mathrm{CaCl} 2$ solution were transferred to the reactor and submitted to agitation. Four different experiments were conducted to evaluate the efficiency of the exchangeable sodium percentage at different temperatures and reaction times. The first experiment was conducted at room temperature 25 ${ }^{\circ} \mathrm{C}$ for 1 hour (5A1), the second was held at $100{ }^{\circ} \mathrm{C}$ for 1 hour $(5 \mathrm{~A} 2)$ at reflux, the third was performed at room temperature $\left(25^{\circ} \mathrm{C}\right)$ for 24 hours $(5 \mathrm{~A} 3)$ and the fourth experiment was carried out at $100^{\circ} \mathrm{C}$ for 24 h (5A4) also under reflux. After these procedures, the samples were washed, filtered and dried similar to that of zeolite 4A. Then, the zeolite 5A, obtained by ion exchange, as well as the zeolite $4 \mathrm{~A}$ and the starting materials, were characterized using the techniques of $\mathrm{X}$-ray fluorescence (XRF), Xray diffraction (XRD); the indentification of crystaline phases was done using the software X'pert High Score. Morphological analyses of zeolites were performed using scaning electron microscopy with energy dispersive X-ray spectroscopy (SEM/EDX) and Fourier transform infrared spectroscopic (FTIR) (Boca Santa et al. 2013). Thermal stability of the obtained zeolitic material was determined by the techniques of thermal gravimetric analysis (TGA) and differential scanning calorimetry (DSC) in a thermogravimetric analyzer model
DTG-60 Shimadzu. After these characterizations, the composition and the cation exchange capacity of the zeolite $\mathrm{NaA}$ was determined by the atomic absorption technique. Sodium solutions were analyzed in a Cole-Parmer flame photometer, and calcium in a PinAAcle 900T atomic absorption spectrometer. The determination of exchange of $\mathrm{Na}^{+}$inos with $\mathrm{Ca}^{2+}$ ions was performed taking into account the influence of contact time and temperature. Based on the results of atomic absorption, cation exchange percentage (CEP) was calculated by the difference in sodium content of the sample and defined by Equation 1.

$$
C E P=100 . C_{0}-C_{F} / C_{0}
$$

where $\mathrm{C}_{0}$ and $\mathrm{C}_{\mathrm{f}}$ are the initial (before exchange) and final (after exchange) concentrations of sodium, respectively.

\section{RESULTS AND DISCUSSION}

The chemical composition of waste before and after the purification process was determined by X-ray fluorescence, and the results as oxide percentage are described in Table 1. The figures show a significant decrease in the amount of $\mathrm{CaO}$, from $32.35 \%$ in raw waste to 5.56 and $2.03 \%$, after treatment with $\mathrm{HCl}$ at 1.5 and $1.8 \mathrm{~mol}^{-\mathrm{L}^{-1}}$, respectively. Similar results were previously reported by Boca Santa et al. (2013). As can be seen, higher $\mathrm{HCl}$ concentrations improved efficiency of the $\mathrm{CaO}$ (calcite) elimination process in waste from the paper industry. High percentages of $\mathrm{SiO}_{2}$ and $\mathrm{Al}_{2} \mathrm{O}_{3}$ were observed for both treatments ( 1.5 and 1.8 mol. $\mathrm{L}^{-}$ $\left.{ }^{1} \mathrm{HCl}\right)$, which are similar to those specified by Santos (1989), i.e., $46.54 \%$ for $\mathrm{SiO}_{2}$ and $39.5 \%$ for $\mathrm{Al}_{2} \mathrm{O}_{3}$. The in natura waste sample was dried in the oven at $100^{\circ} \mathrm{C}$ for $24 \mathrm{~h}$ to remove humidity and followed by XRF analysis; but as the sample had some amount of organic matter (pulp), this may have increased the ignition loss, compared to the other samples. However, the metakaolin, obtained from the treated waste and calcined at $850^{\circ} \mathrm{C}$, showed the smallest loss of mass. Raw paper waste has crystalline phases corresponding to calcite and kaolinite (Figure 1a). After acid washing and calcination, peaks corresponding to calcite and kaolinite disappeared, indicating the purification and processing of kaolin into metakaolin (Figure 1). The best results were obtained in the treatment with $\mathrm{HCl}$ at $1.8 \mathrm{~mol} . \mathrm{L}^{-1}$; therefore, zeolite $4 \mathrm{~A}$ was synthesized based on this sample. After waste purification with $\mathrm{HCl}$, the remaining solution was evaporated and the resulting salt $\left(\mathrm{CaCl}_{2}\right)$ was characterized by the XRD technique 
(Figure 2). There was high purity, characterized by calcium chloride peaks; therefore, this material was used to obtain zeolite $5 \mathrm{~A}$. The results in oxide of XRF analyses of $4 \mathrm{~A}$ and $5 \mathrm{~A}$ zeolites are shown in Table 1. According to the results there was exchange of $\mathrm{Na}$ by $\mathrm{Ca}$ ions in an amount greater than $50 \%$. The XRF data are in accordance with the results obtained by atomic absorption analysis described in Table 2 .

The XRD patterns of the zeolite samples are shown in Figures 3 and 4, where two $\mathrm{NaOH}$ concentrations were tested for the synthesis of the zeolite 4A. The data coincide with those published by the International Zeolite Association (2015). When the peaks found in the XRD patterns coincide with the simulated peaks and comparable intensity, then the sample does contain the desired zeolite with high purity (Guisnet and Ribeiro, 2004). Figure 3 shows the XRD patterns of the samples produced at a concentration of 1.25 mol.L-1 $\mathrm{NaOH}$ at different temperatures and crystallization times. The XRD pattern did not show any crystal structure relative to zeolite $4 \mathrm{~A}$ at the temperature of $80{ }^{\circ} \mathrm{C}$ (Figure 3 (a1) and (a2). The product was similar to the starting material. There is an amorphous halo

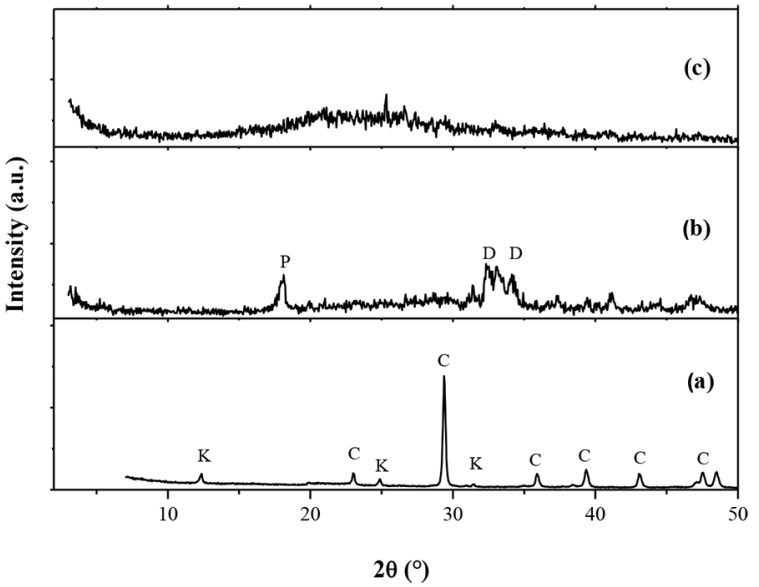

Figure 1. XRD pattern of fresh waste (a) and waste after purification in $\mathrm{HCl}$ at a concentration of $1.5 \mathrm{~mol} . \mathrm{L}^{-1}(\mathrm{~b})$ and $1.8 \mathrm{~mol} . \mathrm{L}^{-1}$ (c), at a temperature of $850{ }^{\circ} \mathrm{C}$. C - Calcite (JCPDS No. 01-072-1214), K - Kaolinite (JCPDS No. 00-001-0527), P - Calcium Hydroxide (JCPS No. 01-087-0673), D Dialuminium silicate oxide (JCPDS No. 01-089-0886).

in the XRD pattern of Figure 3 (b1), which indicates that the crystallization performed at $150{ }^{\circ} \mathrm{C}$ for 4 hours was not complete. However, there were diffraction peaks corresponding to the zeolite $4 \mathrm{~A}$. The sample

Table 1. Percentage values of chemical components in oxides present in fresh waste and in waste after purification with $\mathrm{HCl}$ at concentrations of 1.5 and $1.8 \mathrm{~mol} . \mathrm{L}^{-1}$

\begin{tabular}{|c|c|c|c|c|c|}
\hline Oxides & in natura & $1.5 \mathrm{~mol} . \mathrm{L}^{-1}$ & $1.8 \mathrm{~mol}^{-\mathrm{L}^{-1}}$ & Zeolite 4A & Zeolite 5A \\
\hline $\mathrm{SiO}_{2}$ & 7.69 & 49.57 & 53.61 & 42.14 & 42.28 \\
\hline $\mathrm{Al}_{2} \mathrm{O}_{3}$ & 6.08 & 38.87 & 37.32 & 27.98 & 28.08 \\
\hline $\mathrm{CaO}$ & 32.35 & 5.56 & 2.03 & 1.00 & 5.80 \\
\hline $\mathrm{Fe}_{2} \mathrm{O}_{3}$ & 0.17 & 1.55 & 1.64 & 0.94 & 0.87 \\
\hline $\mathrm{K}_{2} \mathrm{O}$ & $<0.05$ & 0.24 & 0.48 & 0.29 & 0.27 \\
\hline $\mathrm{MgO}$ & 0.62 & 1.43 & 1.63 & 1.04 & 1,05 \\
\hline $\mathrm{MnO}$ & $<0.05$ & 1.38 & $<0.05$ & $<0.05$ & $<0.05$ \\
\hline $\mathrm{Na}_{2} \mathrm{O}$ & 0.07 & 0.08 & 0.34 & 15.75 & 10,01 \\
\hline $\mathrm{P}_{2} \mathrm{O}_{5}$ & 0.11 & 0.25 & 0.16 & 0.08 & 0.07 \\
\hline $\mathrm{TiO}_{2}$ & 0.15 & $<0.05$ & 1.84 & 0.76 & 0.68 \\
\hline $\mathrm{BaO}$ & $<0.1$ & $<0.05$ & $<0.1$ & - & - \\
\hline $\mathrm{Co}_{2} \mathrm{O}_{3}$ e $\mathrm{Cr}_{2} \mathrm{O}_{3}$ & $<0.1$ & $<0.1$ & $<0.1$ & - & - \\
\hline $\mathrm{ZnO}, \mathrm{PbO}$ e $\mathrm{SrO}$ & $<0.1$ & $<0.1$ & $<0.1$ & - & - \\
\hline $\mathrm{ZrO}_{2}+\mathrm{HfO}_{2}$ & $<0.1$ & 0.23 & 0.32 & - & - \\
\hline LOI & 52.64 & 0.8 & 0.60 & 10.01 & 10.88 \\
\hline
\end{tabular}

Table 2. Atomic absorption spectrometric analysis of zeolite $5 \mathrm{~A}$.

\begin{tabular}{|c|c|c|c|c|c|}
\hline Zeolite & $\mathrm{Na}^{+}(\%)$ & $\mathrm{Ca}^{+2}(\%)$ & $\begin{array}{c}\text { Temperature exchange } \\
\text { (h) }\end{array}$ & Time Exchange $\left({ }^{\circ} \mathrm{C}\right)$ & Cation Exchange (\%) \\
\hline $4 \mathrm{~A}$ & 14,9 & 0,37 & - & - & 100 \\
\hline $5 \mathrm{~A} 1$ & 6,95 & 3,30 & 1 & 25 & 53,35 \\
\hline $5 \mathrm{~A} 2$ & 6,84 & 3,66 & 1 & 100 & 54,09 \\
\hline $5 \mathrm{~A} 3$ & 6,71 & 4,40 & 24 & 25 & 54,96 \\
\hline $5 \mathrm{~A} 4$ & 6,61 & 3,61 & 24 & 100 & 55,63 \\
\hline
\end{tabular}




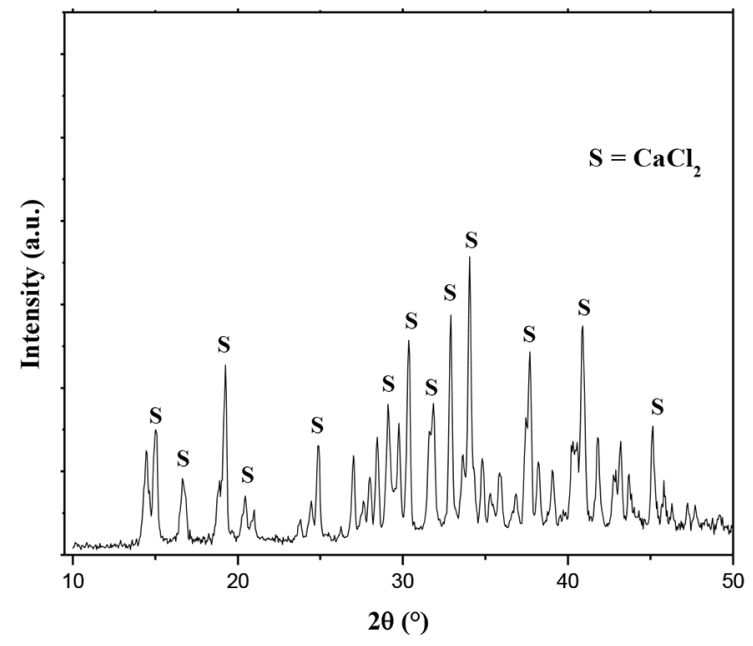

Figure 2. XRD pattern of calcium chloride obtained by evaporating the remaining solution from the purification process of waste paper. S Calcium Chloride (JCPDS No. 00-049-1092 and 00-012-0056).

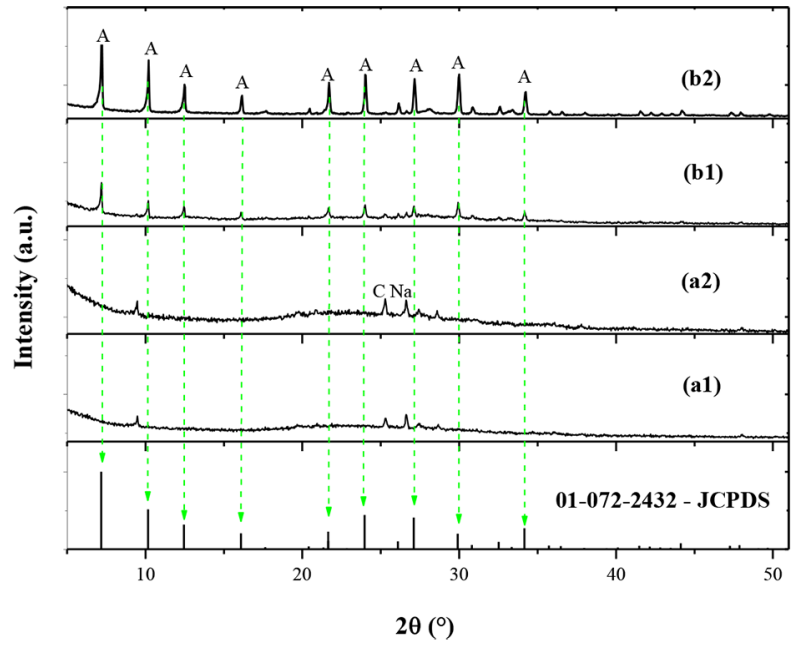

Figure 3. DRX pattern of zeolites produced from waste at the concentration of $1.25 \mathrm{~mol} . \mathrm{L}^{-1} \mathrm{NaOH}$ at the temperature of $80 \mathrm{oC}$ and crystallization times of 4h (a1) and 6h (a2), C - cristobalite (JCPDS No. 01-089-3607), N $\mathrm{NaOH}$ (JCPDS No. 01-075-0642) and at the temperature of $150{ }^{\circ} \mathrm{C}$ and times of $4 \mathrm{~h}$ (b1) and $6 \mathrm{~h}$ (b2), A = zeolite A (JCPDS No. 01-072-2432).

synthesized at $150{ }^{\circ} \mathrm{C}$ for 6 hours (b2) showed the best results with good crystallinity and purity with well defined peaks characteristic of zeolite $4 \mathrm{~A}$ with $2 \theta$ values at: $7.18^{\mathrm{o}} ; 10.17^{\mathrm{o}} ; 12.46^{\mathrm{o}} ; 16.11^{\mathrm{o}} ; 21.85^{\mathrm{o}} ; 24^{\mathrm{o}} ; 26.2^{\mathrm{o}}$; $27.2^{\circ}, 30^{\circ}, 30.9^{\circ} ; 31.7^{\circ} ; 32.6^{\circ} ; 33.4^{\circ}$ and $34.7^{\circ}$ as were reported by Treacy and Higgins (2001). According to the XRD patterns shown in Figure 4, the samples (a1) and (a2) synthesized at $80^{\circ} \mathrm{C}$ for 4 and 6 hours present only phases relative to zeolite $\mathrm{A}$, without the formation of other crystalline phases. All other experimental conditions (b1) and (b2) show peaks relative to other phases, showing that the material is composed of the $\mathrm{A}$ and $\mathrm{X}$ zeolitic phases. The morphological structure of the zeolite can be affected by molar composition

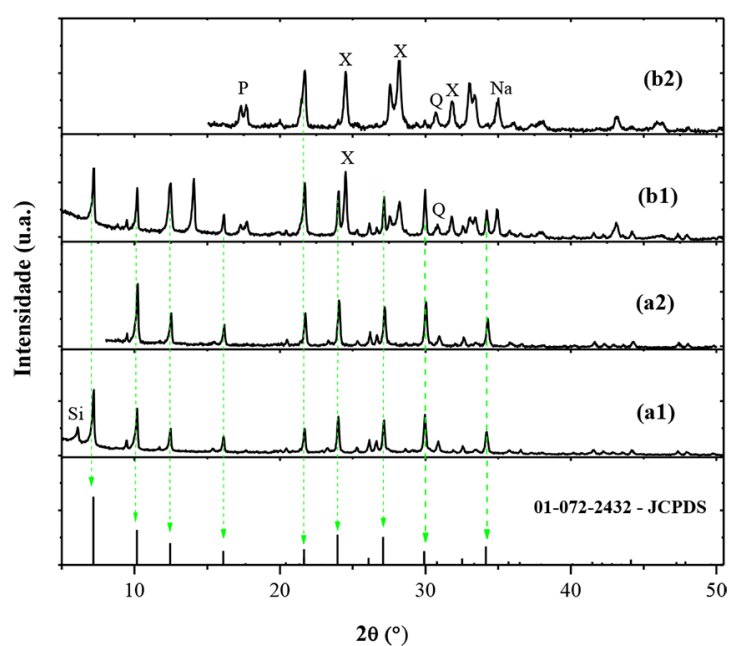

Figure 4. DRX pattern of zeolites produced from waste at the concentration of $4.25 \mathrm{~mol} . \mathrm{L}^{-1} \mathrm{NaOH}$ at the temperature of $80 \mathrm{oC}$ and crystallization times of $4 \mathrm{~h}$ (a1) and $6 \mathrm{~h} \mathrm{(a2)}$ and at the temperature of $150{ }^{\circ} \mathrm{C}$ and times of $4 \mathrm{~h}$ (b1) and $6 \mathrm{~h}$ (b2). O - silicon oxide (JCPDS No. 00-032-0993 and 01079-0564), A = zeolite A (JCPDS No. 01-072-2432and 01-073-2340), Q quartzo (JCPDS No. 00-001-0649), N - NaOH (JCPDS No. 01-075-0642) and X - zeolite X (JCPDS No. 00-028-1036).

ratios $\left(\mathrm{SiO}_{2} / \mathrm{Al}_{2} \mathrm{O}_{3}\right.$ and $\left.\mathrm{Na}_{2} \mathrm{O} / \mathrm{H}_{2} \mathrm{O}\right)$, synthesis temperature and crystallization time (Tanaka et al., 2002). Furthermore, the amount of silicon dissolved from metakaolin may have been higher than that of aluminum, exceeding the appropriate range of $\mathrm{SiO}_{2} /$ $\mathrm{Al}_{2} \mathrm{O}_{3}$ molar ratio in zeolite A synthesis, thus favoring the appearance of the X phase (Wang et al., 2008). It was found that the higher the concentration of $\mathrm{NaOH}$ used, the lower the crystallization temperatures that are required for zeolite $4 \mathrm{~A}$. Zeolite $4 \mathrm{~A}$ was obtained as the main crystalline phase at the lowest studied concentration of $\mathrm{NaOH}\left(1.25 \mathrm{~mol} . \mathrm{L}^{-1}\right)$. Thus, the sample synthesized with $1.25 \mathrm{~mol} . \mathrm{L}^{-1} \mathrm{NaOH}$ at $150^{\circ} \mathrm{C}$ for 6 hours was chosen for further characterizations and for the subsequent step for obtaining zeolite $5 \mathrm{~A}$ by means of ion exchange.

Figure 5 shows the FTIR spectrum of the zeolite $4 \mathrm{~A}$; the band at $3454 \mathrm{~cm}^{-1}$ was observed and attributed to zeolitic water. The presence of zeolitic material was confirmed through the bands at 1102 and $1008 \mathrm{~cm}^{-1}$; these bands located near $1000 \mathrm{~cm}^{-1}$ characterize Si-OAl (Freitas et al., 2011). The bands around 680, 550 and $456 \mathrm{~cm}^{-1}$ indicate the crystallization of zeolite A. The band at $680 \mathrm{~cm}^{-1}$ represents typical symmetrical stretches of the primary internal vibrations T-O, where $\mathrm{T}$ can be silicon $(\mathrm{Si})$ or aluminum $(\mathrm{Al})$. The next band at $550 \mathrm{~cm}^{-1}$ is connected with the vibration of the fourtetrahedra double ring (DR4), which is dominant in the secondary construction unit of the zeolite A structure (Markovic et al., 2003). A band at $463 \mathrm{~cm}^{-1}$ characterizes the internal vibration of D4R (Andrade and Silva, 
2011). There was also a band located at $800 \mathrm{~cm}^{-1}$ related to the Si-O-Al bonds present in metakaolin (Barbosa et al., 1999), which possibly did not completely react, these results confirm the data gathered by XRD analysis. After the presence of the major chemical bonds was confirmed in the zeolitic material obtained, its thermal stability was determined by TGA and DSC analyses (Figure 6). Thermogravimetric analysis showed endothermic weight loss due to dehydration. This loss began at $50^{\circ} \mathrm{C}$ and showed a sharp deflection starting around $85{ }^{\circ} \mathrm{C}$ and stretching up to $170{ }^{\circ} \mathrm{C}$, reaching its maximum value $(17 \%)$ at the temperature of $650^{\circ} \mathrm{C}$. Based on the loss of water of dehydration, proportions of the mineral present in the zeolitic sample can be estimated to be around $83 \%$ (Freitas et al., 2011). The zeolite also showed an exothermic peak in the region close to $900{ }^{\circ} \mathrm{C}$; these peaks are common in zeolites, and refer to the formation of amorphous aluminosilicate by destruction of the structure of the zeolite and its subsequent recrystallization into a new phase (Kosanovic et al., 1998; Maia et al., 2007). By means of scanning electron microscopy, it was found that both zeolites, obtained from sodium (4A) and by ion exchange (5A), have cubic morphology (Figure 7), which is typical of zeolites A (Loiola et al., 2012). The crystals observed in the micrographs are isolated and have a small amount of amorphous material, possibly unreacted metakaolin. Figure $7 \mathrm{~b}$ and $7 \mathrm{~d}$ shows the semi-quantitative results for EDX, the extent of exchange of calcium cations with sodium cations in zeolite samples, which resulted in $8.09 \%$ $\mathrm{Na}^{+}$and $1.27 \% \mathrm{Ca}^{+2}$ for zeolite $4 \mathrm{~A}$ and $2.16 \% \mathrm{Na}^{+}$ and $7.61 \% \mathrm{Ca}^{+2}$ for zeolite 5A. Table 2 shows the effect of temperature and time on the efficiency of the cation exchange of the zeolite $4 \mathrm{~A}$. The zeolite $4 \mathrm{~A}$ is equivalent to the initial sample before the exchange. These data show that the samples submitted to 1 hour contact show a good result in obtaining the desired zeolite. According to the analyses performed, the best result was achieved for the sample at the temperature of $100{ }^{\circ} \mathrm{C}$ for 24 hours; however, for the other samples, the differences were not significant with variations of time and temperature.

\section{CONCLUSION}

The waste from the paper industry has proved to be an excellent raw material for the production of zeolite $\mathrm{A}$ and all the components present in the waste can be used. Therefore, this process is a viable alternative

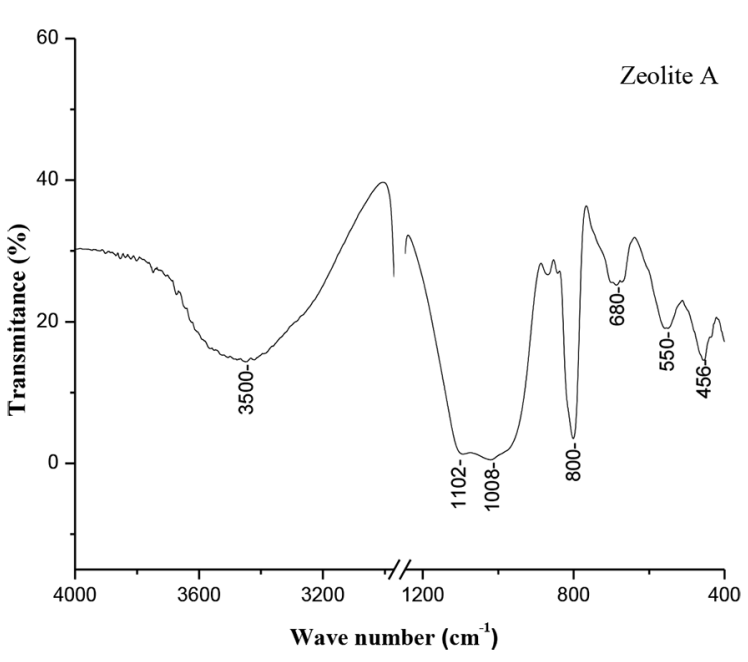

Figure 5. Absorption spectra in the infrared region of zeolite 4A.

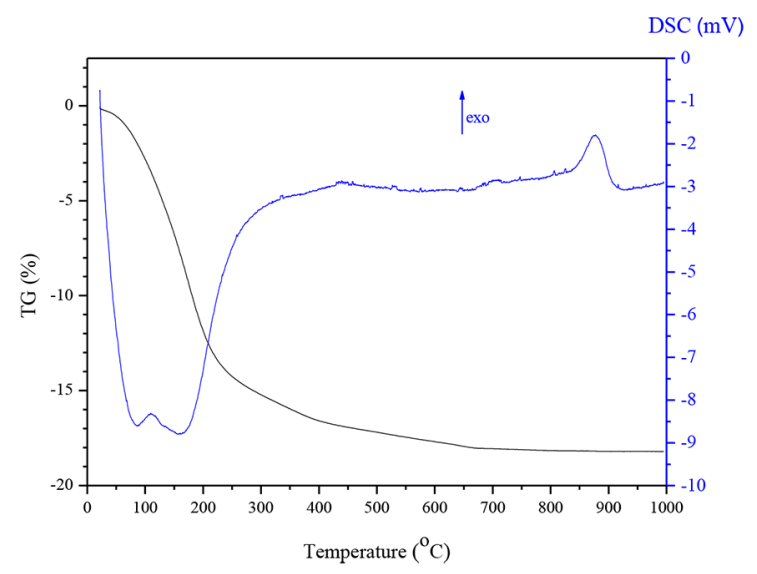

Figure 6. Thermal analysis of zeolite 4A - TG and DSC.

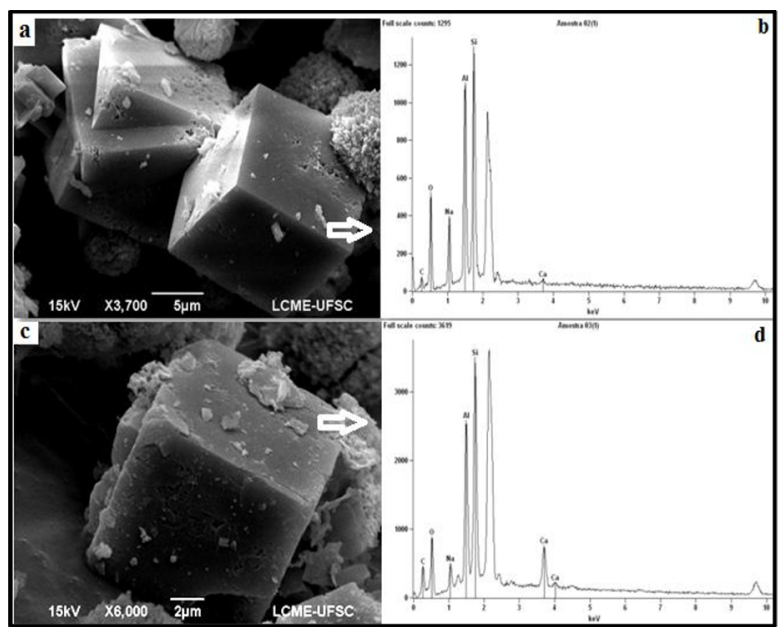

Figure 7. Scanning electron micrograph of the sample of zeolite 4A (a) with $3700 \mathrm{x}$ magnification, and of zeolite $5 \mathrm{~A}$ (c) with $6000 \mathrm{X}$ magnification, and EDX (b) and (d) analysis of elements present in the zeolites. 
to minimize environmental impacts. In the process performed at the concentration of $4.25 \mathrm{~mol} . \mathrm{L}^{-1} \mathrm{NaOH}$, a mixture of phases was obtained with different zeolitic phases (A, X and hydroxysodalite). At the $\mathrm{NaOH}$ concentration at 1.25 mol. $\mathrm{L}^{-1}$, only zeolite $\mathrm{A}$ was formed; however, at the lower synthesis temperature $\left(80{ }^{\circ} \mathrm{C}\right)$, no crystals were formed for the established conditions. These results indicate that, for the process of cation exchange, it is not necessary to use long times and high temperatures, since the exchange between $\mathrm{Na}^{+}$ions of the zeolite is made quickly by $\mathrm{Ca}^{2+}$ ions present in the solution.

\section{ACKNOWLEDGMENTS}

The authors thank CAPES (Coordination for the Improvement of Higher Education Personnel - SD), Federal University of Santa Catarina and LCMEUFSC for their support to this research.

\section{REFERENCES}

Andrade, J. C. R. A.; Silva, L. R. D., Nitrate occluded in zeolite 4A: absorption and leaching of nitrogen in the cultivation of corn, Química Nova, 34, 15621568, (2011).

Barbosa, V. F. F.; Mackenzie, K. J. D.; Traumaturgo, C., Synthesis and Characterization of Sodium Polysialate Inorganic Polymer Based on Alumina and Silica. Second International Conference Geopolymére'99, Institut Géopolymère, SaintQuentin, France and I.N.S.S.E.T. Université de Picardie, Saint-Quentin, France, v. 4, p. 65-78 (1999).

Boca Santa, R. A. A.; Bernardin, A. M.; Riella, H. G.; Kuhnen, N. C., Geopolymer Synthetized from Bottom Coal Ash and Calcined Paper Sludge, Journal Cleaner Production, 57 302-307 (2013).

Brazilian Association of Pulp and Paper. http//www. bracelpa.org.br, accessed nov. 15 (2015).

Breck, D. W. Zeolite molecular sieves. New York: John Wiley \& Sons, Inc. (1984).

Cundy, C.S.; Cox, P.A., The hydrothermal synthesis of zeolites: history and development from the earliest days to the present time, Americam Chemical Society, 103 663-701 (2003).

Freitas, V. A. A.; Lima, J. S. V.; Couceiro, P. R. C., Characterization and structural analysis hydroxysodalite synthesized from Amazonian soil samples, Cerâmica, 57 281-287 (2011).
Grecco, S. T. F.; Rangel, M. C. R. Hierarchicallystructuredzeolites, Química Nova, 36 131-142 (2013).

Guisnet, M.; Ribeiro, F. R., Zeólitos: um nanomundo ao serviço da catálise. Lisboa: Fundação Calouste Gulbenkian, (2004).

International Zeolite Association - IZA. http://www. iza-structure.org/databases/, (accessed, nov, 2015).

Jamieson, H. L.; Yin, H.; Waller, A.; Khosravi, A.; Lind, M. L., Impact of acids on the structure and composition of Linde Type A zeolites for use in reverse osmosis membranes for recovery of urine-containing wastewaters, Microporous and Mesoporous Materials, 201 50-60 (2015).

Kosanovic, C.; Subotic, B.; Smit, I., Thermally induced phase transformations in cationexchanged zeolites 4A, 13X and syntheticmordenite and their amorphous derivatives obtained by mechanochemical treatment, Thermochimica Acta, 317 25-37 (1998).

Loiola, A.R.; Andrade, J.C.R.A.; Sasaki, J.M; Silva, L.R.D., Structural analysis of zeolite NaA synthesized by a cost-effective hydrothermal method using kaolin and its use as water softener, Journal Colloid Interface Science, 367 34-39 (2012).

Lorenzett, D. B.; Neuhaus, M.; Schwab, N. T. Waste management and the rice beneficiation industry, Revista Gestão Industrial, 8 219-232 (2012).

Luna, F. J.; Schuchardt, U., Modifying zeolites for use in catalysis, Química Nova, 24 885-892 (2001).

Maia, A. A. B.; Saldanha, E.; Angélica, R. S.; Souza, C. A. G.; Neves, R.F., The use of kaolin wastes from the Amazon region on the synthesis of zeolite A, Cerâmica, 53 319-324 (2007).

Markovic, S.; Dondur, V.; Dimitrijevic, R., FTIR spectroscopy of framework aluminosilicate structures: carnegieite and pure sodium nepheline, Journal of Molecular Structure, 654, .223-234 (2003).

Melo, C. R.; Riella, H. G.; Kuhnen, N. C.; Angioletto, E.; Melo, A. R.; Bernardin, A. M.; Rocha, M. R.; Silva, L., Synthesis of 4A zeolites from kaolin for obtaining $5 \mathrm{~A}$ zeolites through ionic exchange for adsorption of arsenic, Materials Science and Engeneering: B., 177 345-349 (2012).

Pinheiro, R. M. I; Vieira, C. M. F. I; Rodriguez, R. S. I; Monteiro, S. N., Recycling of waste from the paper production into red ceramic, Revista Matéria, 13 220-227 (2008). 
Rigo, R. T.; Pergher, S. B. C.; Petkowicz, D. I.; Santos, J. H. Z., A new procedure for a zeolite synthesis from natural clays. Química Nova, 32 21-25 (2009).

Santos, P. S. Ciência e tecnologia das argilas, $2^{\mathrm{a}}$ ed. São Paulo: Edgard Blücher Ltda, 1989.

Silaghi, M.C.; Chizallet, C.; RaybauD, P., Challenges on molecular aspects of dealumination and desilication of zeolites, Microporous and Mesoporous Materials, 191 82-96 (2014).

Silva Filho, S. H.; Bieseki, L.; Maia, A. A B.; Pergher, S. B. C., Synthesis of zeolite a with high degree of structural order from a kaolin waste from the Jari region. Perspectiva, 39 67-72 (2015).

Tanaka, H.; Sakai, Y.; Hino, R., Formation of Na-A and $\mathrm{Na}-\mathrm{X}$ zeolites from waste solutions in conversion of coal fly ash to zeolites, Materials Research Bulletin, 37 1873-1884 (2002).

Treacy, M.J.; Higgins, J.B., Collection of simulated XRD powder patterns for zeolites, $4^{\text {a }}$ ed., p. 379, Elsevier, Amsterdam, the Netherlands, (2001).
Triguero, A.; Álvarez-Aledo, C.; Cuerva, M. C., Factors Influencing Willingness to Accept Different Waste Management Policies: Empirical Evidence from the European Union. Journal of Cleaner Production, 138 38-46 (2016). DOI: 10.1016/j. jclepro.2016.05.119

Viera, L. H.; Rodrigues, M. V.; Martins, L., Seedassisted behavior of zeolite crystallization, Química Nova, 37 1515-1524 (2014).

Wang, C. F.; Li, J. S.; Wang, L. J.; Sun, X. Y., Influence of $\mathrm{NaOH}$ concentrations on synthesis of pure-form zeolite A from fly ash using two-stage method, Journal Hazardous Materials, 155 58-64 (2008).

Zhang, G, X.; Tang, D.; Jiang, G., Synthesis of zeolite $\mathrm{NaA}$ at room temperature: The effect of synthesis parameters on crystal size and its size distribution, Advance Powder Technology, 24 689-696 (2013). 